JOST1390FR

\title{
Counter-factual Scenario Planning for Long-range Sustainable Local Level Tourism Transformation
}

\begin{abstract}
:
Many traditionally agricultural dependent economies have transformed towards service industries, such as tourism. This transformation resulted in significant impacts upon economies, communities and the environment. However, existing indicators to measure the impacts of tourism on regions have not been examined across the transformation process, leaving a gap in the understanding of long-range planning for tourism. Therefore, this paper investigates the relationship between economic, social and environmental indicators across the three main phases of tourism transformation. The three broad phases of tourism transformation can be observed to commence (inception), grow (construction), and then enter a steady state (urbanisation). To investigate this, this research surveyed 303 residents across three local areas at different stages of economic development and tourism dependency, to develop tourism, economic, social and environmental indicators. Employing counter-factual data, generalised ordinal logistic regression models were used to predict and compare the impact of changes in tourism on the economy, society and the environment across the regions. The findings indicate that the relationships between tourism and the triple bottom line differ depending on the stage of development. This research provides insight into local level long-range planning, which can enable more sustainable tourism transformation, and explores avenues for future research.
\end{abstract}

Keywords: tourism transformation, long-range planning, scenario analysis 


\section{Counter-factual Scenario Planning for Long-range Sustainable Local Level Tourism Transformation}

\section{Introduction}

The world is becoming more complex, sophisticated and competitive, fuelled by economic growth and fluctuations, technological change and the realisation that many resources are so scarce that they could disappear forever (Dwyer, Edwards, Mistilis, Roman \& Scott, 2009). Decisions made today shape the future, and thus there is a need for longrange planning when setting policies and instigating change to ensure sustainable tourism development (Alexandra \& Riddington, 2007). Yet, predicting the future is complex and elusive, especially in the long-term. Scenario planning allows researchers to investigate, anticipate and predict a range of possible futures in this shifting global landscape.

Tourism is viewed as a way to transform, restructure and deliver sustainable economic growth for declining regions, particularly at the local level (McLennan, Ruhanen, Ritchie \& Pham, 2012). Transformation theory has emerged as a tool to understand this process of long-term economic structural change, with growing interest from tourism researchers (Hall, 2004; Pavlovich, 2003). An example of transformation is the structural shifts that occur as an economy transforms from an agriculturally dominated to a tourism dependent region. Transformational change is an on-going process considered to take place in three main re-occurring phases that commences in a steady state, undertakes change and then enters a new equilibrium state before recommencing the next transition (Sergeyev \& Moscardini, 2006). When applied to a tourism destination, three broad phases of tourism transformation can be observed to commence (inception), grow (construction), and then enter a steady state (urbanisation), with on-going changes defining the exact nature of the region's growth path (McLennan, 2009). The process of growth and change must continue, or the region will decline.

Although seeking a smooth transition towards tourism transformation, many regions have pursued inappropriate tourism policies, with significant negative impacts upon local economies, communities and the environment, due to short term tourism development activities (Sorenson \& Epps, 2003). As the understanding of long-run change processes is incomplete, and perhaps becoming even less understood in an increasingly complex world, 
there are continued observations of inefficiencies, and in some regions, decline (Holmes, Charles-Edwards \& Bell, 2005). In the tourism field the existing indicators used to measure the impacts of tourism on local economies are under-examined across the transformation process, particularly at the local level, leaving a gap in the understanding of long-range planning for tourism transformation. Consequently, this paper investigates the relationship between tourism and the triple bottom line, within and between the three main phases of long-range tourism transformation.

\section{Literature Review}

Many destinations around the world have relied on tourism as an economic development strategy. However, this process of transformation is often problematic and unsustainable, partially due to limited knowledge surrounding the process (Alexandra \& Riddington, 2007). Transformational change in the tourism industry needs to be planned to ensure positive outcomes with minimum negative impacts on the economy, society and environment. Often economic transformation is more readily observed at the local level, where declines can have the greatest impact (Milne \& Ateljevic, 2001). Thus a local level approach is required (Schianetz, Kavanagh \& Lockington, 2007).

In the tourism literature, transformation theory has evolved from a social tourism theory to one considering tourism destination change. Predominantly, tourism transformation has been examined through qualitative case studies focusing on social dynamics, single tourism products and on multiple tourism products at regional and country destination levels (McLennan et al., 2012). Transformation theory has emerged as a key destination evolutionary theory; it is a holistic and flexible approach to strategic destination management that describes dynamic system change and considers broader factors, such as the triple bottom line (Pavlovich, 2003). However, the literature suggests that the theory requires further development to be a useful tool for managing destinations.

A key concept of transformation is cyclical time, which can be observed as repetitive patterns in structures (Land, 1973). Cyclical time has been considered in the broader literature but this has not fully answered questions surrounding recurrence or repetition in structures (Corpataux \& Crevoisier, 2007; Knapp, 1999). In tourism research, the number of investigations into the cyclical time aspects of the tourism transformation process are limited 
(McLennan et al., 2012). Models of the future have been criticised as reactive and departing from reality over the long-run due to their basis on historical data (Prideaux, Laws \& Faulkner, 2004), highlight the need for further studies into the nature of cyclical time.

The tourism industry has some characteristics that apply to all destinations and there is evidence that these depend on the phase of tourism transformation (Yeoman, Lennon, Blake, Galt, Greenwood \& McMahon-Beattie, 2008). It has been hypothesised that a region's economic development stage can determine its development patterns and its ability to cope with particular impacts (Buhalis, 2000). Yet, it remains unclear whether different stages of a tourism destination's development are homogenous (Scott, 2003). A tourism destination's transformation process and its relationship to the region's economy, society and environment, needs further investigation to enhance long-range tourism planning (McLennan et al., 2012).

Since the development of early tourism development models, tourism impacts have been widely discussed in the literature (Moyle, Croy \& Weiler, 2010). It has been argued that the economic benefits of tourism can outweigh its negative social and environmental impacts (Diedrich \& Garcia-Buades, 2009), particularly if tourism is a dominant economic sector (Tooman, 1997). Campbell (1999) indicated that positive support for tourism development was for economic development more broadly, rather than tourism specifically. Research suggests that high dependency on tourism makes residents favourable towards tourism development (Harrill, 2004).

Some researchers have found that tourism can have positive impacts (Andereck \& Vogt, 2000), or achieve balance between positive and negative impacts (Dickinson \& Robbins, 2008). In contrast, others argue that negative impacts arise early in the development process and have profound impacts on the host community (Moyle et al., 2010). Yet the impacts can change as the region transitions across the development spectrum, often starting out positive and increasingly becoming negative (Butler, 1980). Thus, if tourism has positive or negative impacts across the transformation process remains unclear. This lack of clarity may be due to differences that arise spatially or across the stages of transformation.

Current research in this field includes: developing tourism, economic, social, environmental and climate change indices (Scott \& McBoyle, 2001), devising adaptation and response strategies to impacts (Gössling \& Schumacher, 2010), undertaking key tourism stakeholder surveys and workshops (Turton, Dickson, Hadwen, Jorgensen, Pham, Simmons, Tremblay \& Wilson, 2010), undertaking hypothetical forecasts into the long-range future, and 
utilising scenario models (Pham, Simmons \& Spurr, 2010). To date, the tourism impact literature has been trending towards the use of scenario planning with popular techniques being Computable General Equilibrium (CGE) modelling (e.g., Pham et al., 2010; Yeoman et al., 2007), Systems Dynamics Modelling (e.g., Chen, 2004) and Delphi surveys or participatory scenario planning (e.g., Daconto \& Sherpa, 2010). Despite this emerging body of literature, the relationship between tourism and the triple bottom line remains underresearched. In particular, an understanding of these relationships and how they may vary over the long-run is far from complete (McLennan et al., 2012).

Scenario modelling can provide insights into how relationships may change if there are modifications to certain variables. However, while scenario modelling is a rapidly emerging field, in tourism research it still requires further development (Prideaux et al., 2004). For example, there has been few scenario models investigating changes over the very long-run and there has been little application of counterfactual scenario planning utilising regression. Consequently, this paper employs counterfactual scenario planning using generalised ordinal logistic regression (GOLR) to explore the impact of tourism on the triple bottom line across the three main phases of the tourism transformation process.

\section{Method}

\section{The Case Studies Regions}

This research employed a case study methodology, a recognised method in tourism research (Akama \& Kieti, 2007). Using secondary quantitative statistics and qualitative historical analysis, three case studies of the Murweh Shire, Hervey Bay City and Gold Coast City in Queensland, Australia, were selected. State and national level spatial differences were minimised by selecting regions only from within Queensland. The Murweh Shire represents the inception phase of tourism transformation due to its small agriculturally dominated service centre economy, constrained access and isolation issues (Murweh Shire Council, 2005). Hervey Bay City was selected as the construction phase for its rapid tourism growth; it has emerged as a premier tourist destination in Queensland, though far smaller than the Gold Coast in both economic size and tourism visitation (Holmes et al., 2005). Gold Coast City represents the urban phase due to its developed economy and mature tourism industry that has become increasingly more government guided (Russell \& Faulkner, 2004). 


\section{The Resident Perception Survey}

The survey tool was a mixed-mode self-completion questionnaire, conducted online (via Survey Monkey) and in hard copy. The questionnaire collected a series of statements relating to the community's perception of the tourism industry, the regional economy, environment and society. This built on an established body of literature relating to measuring resident perceptions, which has had a focus on developing tourism, economic, social and environmental indexes and scales; specifically social impact assessments (Ap \& Crompton, 1998; Faulkner \& Tideswell, 1997; Fredline, Deery \& Jago, 2005), environmental indicators (Organisation for Economic Cooperation \& Development, 2008) and community surveys (Gladstone Regional Council, 2008; New Zealand's City Councils, 2008). The statements were collected via Likert-type scales, ranking responses from 1 'Strongly Agree' to 5 'Strongly Disagree'. To ensure validity, the questionnaire underwent an expert panel review and pilot testing in a fourth Queensland region.

The survey took a stratified random sample of residents, aged 15 and over, from the three local areas. Respondents were selected by systematically sampling from the address listings within the Australian White Pages Residential Directory across all three local areas. A panel provider also supplied additional respondents. Newspaper advertisements and media releases were published in each region to raise awareness of the study and encourage participation. The survey achieved 303 responses; 98 in the Murweh Shire, 93 in Hervey Bay and 115 in the Gold Coast. These sample sizes satisfies the recommended minimum of between 60 and 100 required for GOLR modelling (Long, 1997). To further improve representativeness, the data was weighted using sampling weights by age and sex to the resident population in each of the three local areas. Overall response rates varied: $15 \%$ for the Murweh Shire, $14 \%$ for Hervey Bay and 5\% for the Gold Coast. The literature notes that survey response rates have declined (Sheehan, 2001). Other likely factors include survey fatigue and attrition from the panel providers distribution lists, as well as time and resource restrictions, flooding in one of the case study regions and achievement of the minimum sample which restricted the survey period. This response rate was obtained despite snowball sampling, follow-up reminders and incentives to participate. Therefore, there is a possibility of non-response bias, particularly towards respondents more interested in the subject. 


\section{Index development}

Four indexes of tourism and the economy, society and environment were developed to reduce the number of variables and simplify the econometric models. The indicators were developed by reverse coding the negative statements from the resident survey, summing across the variables that related to each key indicator set and then dividing by the number of variables in the set. Only essential variables were included to reduce the chance of corrupting the index and the scaling rules were kept simple to avoid errors associated with statistical sophistication (Simmons, Yonk \& Fawson, 2010).

An assessment of the reliability and dimensionality of the indexes was undertaken using Cronbach's alpha and Principal-Component Factor (PCF) analysis. The society and environment indexes were quite reliable with a Cronbach's alpha of 0.8. The tourism and economic indexes Cronbach's alpha of 0.6 and 0.7 , respectively, satisfy the precision threshold of 0.6 suggested by Asah (2008).

While a scale is confined to being uni-dimensional, an index such as those developed here, can be multi-dimensional. Thus, it was expected that the indexes would be measuring multiple constructs and the PCF results indicate that this is the case, with the Tourism, Economy, Society and Environment indexes retaining two, two, four and five factors, respectively. Indeed, it was predicted that the Tourism and Economic indexes would be measuring a joint construct, given that tourism is an economic sector. To investigate this supposition, the Economic Index was combined with the Tourism Index and re-analysed using PCF analysis. The results retained only three factors, rather than four, ergo supporting the theory that the Tourism Index measures a construct similar to the Economic Index. This indicated that the variables associated with the factor shared by both the Economic and Tourism Index would not result in an appropriate relationship analysis. This is due to multicollinearity, which occurs when two or more variables are highly correlated and results in unstable estimation of the coefficients (Chatterjee \& Hadi, 2006). Thus, the variable of interest selected for the counter-factual scenarios was the one that was not related to the Economic Index. That is, the variable Tourism2 with a factor loading of 0.94 for the secondary factor in the Tourism Index was considered to be the best measure for changes in the tourism industry (Tourism Index) that were not related to the economy (Economic Index), thereby reducing multi-collinearity. 


\section{Data analysis techniques}

The data was analysed using Adjusted Wald tests, Generalised Ordinal Logistic Regression (GOLR) and a counter-factual scenario planning strategy. GOLR allows for robust modelling of ordinal categorical variables (Abreu, Siqueira, Cardoso \& Caiaffa, 2008). The GOLR models developed in this study are based on the proportional odds ordinal logistic regression (OLR) model, only the assumption of parallel lines could be relaxed if necessary.

The OLR model determines the coefficients by estimating the odds of being in one category compared to the odds of being in another category, taking into account the order of the levels (Tarling, 2008). The OLR model assumes that the categorical variable can be expressed through a series of binary variables based on cut-points in the scale, for example, the separation between 1 'Strongly Agree' and 2 'Agree' (Brant, 1990). Therefore, on a 5point scale, there are four corresponding binary logistic models. The OLR model assumes that the true parameter values are the same in each model, thus the parameter estimates from each of the four binary models can be collapsed to provide a single set of parameter estimates (Long \& Freese 2006). This assumption that the binary models in OLR can be pooled is called parallel lines; it implies that the relationship between the independent variables and each level of the dependent variable are proportional. When the assumption of parallel lines does not hold, the independent variables are not consistently related to each categorical level of the dependent variable. In reality the underlying parallel lines assumption that OLR is based on is often violated, suggesting that the model is overly restrictive, ignores some important information and can lead to inconsistent variables (Bender \& Grouven, 1997). As a result, GOLR has been developed to relax the assumption of parallel lines.

Originally, OLR models were developed in this study to determine how tourism relates to the triple bottom line because the dependent variables were ordinal. The parallel lines assumption was tested using the Brant test to determine if the coefficients were equal across the categories (Brant, 1990), under weighted survey data this test is undertaken using Adjusted Wald tests (Williams, 2006). However, some of the OLR models were found to violate the assumption of parallel lines, so to take advantage of the ordinal nature of the data, while not being restricted by this assumption GOLR was employed.

Specifically, the user written gologit2 STATA program developed by Williams (2006) was executed with a survey command to account for the weighting. An auto-fit command was also employed to automatically undertake the Brant test on each independent 
variable and fit the most appropriate model. The program offers three possible model options that are determined by the data: the constrained GOLR model; the unconstrained GOLR model; or the partially constrained GOLR model. The constrained model is where all the independent variables have the parallel lines constraint imposed, while the partiallyconstrained and unconstrained models relax the parallel lines assumption for some, or all, of the independent variables (Lindeboom \& van Doorslaer, 2004).

The GOLR models were extended for the analysis by a counter-factual scenario framework (Imai, Keele, Tingley \& Yamamoto, 2011; Social Science Computing Cooperative, 2006). Counter-factual prediction allows researchers to pose hypothetical questions by estimating a model, then assessing the base case to the predicted model once counter-factual data has been imposed. A base case is the projection of the future assuming business as usual, thus it provides a benchmark for comparison between the scenarios. Several counter-factual experiments were used to predict and compare the impact of changes in tourism on the triple bottom line indexes. The following procedure was applied to generate the counter-factual predictions:

1) Estimate the model through GOLR (using gologit2 command in STATA)

2) Create a new dependent variable containing the predicted values of the base case (using STATA's post-estimation predict command)

3) Modify the independent variable of interest for the scenario. Here, the independent variable of interest was modified from the original values to 1 and then to 5 to represent growth and decline in tourism, respectively.

4) Create a new dependent variable containing the predicted values of the scenario using the predict command

5) Summarize the base case and new dependent variables and compare their ordinal distributions

As discussed above, the independent variable of interest for the scenarios was Tourism2, as it had the least issues with multicollinearity and was logically appropriate. A limitation of using counter-factual data with regression is that it reduces the variation in the sample, which means the scenarios are less likely to differ (Social Science Computing Cooperative, 2006). When using categorical variables, this means that the scenario may cause more observations fall into a certain category or make a set of categories identical, so it may underestimate the impact of a change. However, long-range scenario planning is not a precise 
science, therefore it was only necessary to determine the direction of change and compare it across the case study regions. As there was no requirement to determine precise magnitudes of the change, counter-factual scenario prediction was considered appropriate.

\section{Results}

\section{Overview of the indexes}

While resident perception studies measure subjective concepts, they also reflect reality as impacts are essentially subjective being based on people's real perceptions (Brooks, 2008). Indeed, it has been argued that there is no difference between objective and subjective measures, as objective measures are proxies for subjective indicators (Costanza et al., 2008). This research assumes that subjective measures, such as resident perceptions, reflect reality and the results are discussed from this perspective, rather than from the viewpoint of the residents.

As expected, the indexes revealed that the Gold Coast's tourism industry and economy were the most economically developed, followed by Hervey Bay and the Murweh Shire (Table 1). The economic index shows that the differences between the three region's economies were significant ( $\mathrm{p}=0.021$ ), while the tourism index only indicated a significant difference in the size of the tourism industry between the Murweh Shire and the other two regions $(\mathrm{p}<0.000)$, with there being no significant difference between Hervey Bay and the Gold Coast $(\mathrm{p}=0.176)$. In contrast, the Murweh Shire had the most positive environmental rating $(\overline{\mathrm{x}}=2.8)$, followed by Hervey Bay $(\overline{\mathrm{x}}=3.3)$ and then the Gold Coast $(\overline{\mathrm{x}}=3.6)$, with all three regions environmental indexes differing significantly from each other $(p=0.003)$.

\section{INSERT TABLE 1 HERE}




\section{The relationship between the tourism industry and the economy}

\section{Modelling Results}

GOLR was undertaken to understand the relationships between tourism and the triple bottom line. Table 2 presents the GOLR results estimating the impact of the tourism variables [Tourism1 and Tourism2] on the economy index [Econlikert]. As discussed previously, the unconstrained model contrasts the categories of 'Strongly Agree', 'Agree', 'Neutral' and 'Disagree' with 'Strongly Disagree'. A positive coefficient suggests that the respondents are more likely to be in a higher category (i.e. Strongly Agree or Agree), while negative coefficients indicate that respondents are more likely to be in a lower category (i.e. Disagree or Strongly Disagree).

As GOLR can relax the assumption of parallel lines, it reports the coefficient and standard errors for each category of a variable. The results show that all three models were statistically significant overall (Table 2). The assumption of parallel lines was imposed for Tourism 2 for all three regions, but was violated by Tourism1. Therefore, the coefficients and standard errors are identical for each category of Tourism2, but vary for Tourism1. Tourism3 and Tourism 4 could not be included in the model owing to multi-collinearity. Tourism1 was statistically significant for the Murweh Shire, while Tourism2 was significant for the Gold Coast. Table 1 provides an explanation of what the tourism variables are measuring.

Notably, Tourism1 in the Murweh Shire showed a strong positive relationship with the Econlikert variable, while in Hervey Bay there was moderately negative effect and in the Gold Coast there was a strong negative effect on the dependent variable Econlikert, which is the variable that represents the Economic Index. The Tourism1 variable relates to the residents perceptions of whether tourism is an important industry for their region. This finding suggests that, for the Murweh Shire, tourism is considered an important industry for the region's economy, while in the Gold Coast it is not perceived as important, indicating that as a region diversifies and transforms towards other industries, the tourism industry becomes less economically vital to the region.

\section{INSERT TABLE 2 HERE}




\section{Scenario results}

In line with previous research, tourism was found to be positive for each region's economy (Carmichael, 2000). In particular, the base case results indicated that tourism had the greatest positive economic impact on the Murweh Shire with $41 \%$ of respondents viewing the economy positively, compared to $38 \%$ and $22 \%$ of respondents for the Gold Coast and Hervey Bay, respectively (Figure 1). This result is possibly due to the inception region's lack of industry diversity.

The growth in tourism scenario resulted in a further $24 \%$ of respondents falling within Strongly Agree and Agree for the Murweh Shire, while Hervey Bay increased by $18 \%$ and the Gold Coast's economy increased $13 \%$. The decline in tourism scenario resulted in 23\% fewer respondents viewing the economy positively for the Shire, while the Gold Coast declined $14 \%$ and Hervey Bay declined 13\%. Thus, a small change in tourism could substantially improve or degrade the inception region's economy. While the construction economy is still developing, it is currently heavily dependent on tourism and, at the time of this research, had been experiencing rapid growth. Growth in tourism caused the construction economy to increase further than the decline in tourism caused the economy to retract, suggesting that tourism is a stimulus in the constructing region's economy.

The Gold Coast economy had the greatest variability as a result of a change in tourism, with the scenarios ranging by 42.1 percentage points around the base case estimates. In comparison, the Murweh Shire's scenarios ranged by 38.1 percentage points and Hervey Bay's scenarios ranged by 36.9 percentage points from the base case. This greater variability may reflect the Gold Coast economy's dependence on the tourism industry and that residents recognise more acutely the importance of the industry in terms of the economy when it declines. This supports studies that indicate that urban areas can suffer as a consequence of a loss of tourism and that residents recognise the importance of tourism when there is a lack of economic development, or when tourism is declining (Thompson et al., 2002).

\section{INSERT FIGURE 1 HERE}




\section{The relationship between the tourism industry and society}

\section{Modelling results}

Table 3 presents the GOLR results estimating the impact of the tourism variables [Tourism1, Tourism2, Tourism3 and Tourism4] on the Social Index [Soclikert]. All three models were statistically significant. The parallel lines assumption was imposed for all tourism variables in the Murweh Shire, but only on the Tourism4 variable for the Gold Coast. Tourism2, Tourism3 and Tourism4 were statistically significant for the Shire, while Tourism2 and Tourism3 were significant for the Gold Coast.

\section{INSERT TABLE 3 HERE}

\section{Scenario results}

The literature debates whether tourism development is a positive or negative force for society (Moyle et al., 2010). Researchers have found that tourism economic development has a negative impact on social structures in a region (Gonen, 1981). Others have argued that residents in areas with high concentrations of tourism are less partial to tourism than those in areas with fewer tourists (Duffield \& Long, 1981). Yet, others have concluded that residents perceive the social impacts of tourism to be both positive and negative (Bramwell, 2003). These mixed findings may be the result of spatial differences between regions, or the stage of transformation.

While this research found that all three regions residents' perceptions of their societies were positive and that tourism was impacting positively on their societies, there was no significant difference between the three regions in terms of their societies. Furthermore, when the scenarios were conducted on the three regions, there was little impact on the three societies as a result of tourism: all three modes remaining unchanged at 2 'Agree' (Figure 2). This indicates that the residents are either not impacted by tourism, expect to be impacted by tourism, are accustomed to the impact of tourism on their way of life or consider the positive aspects of tourism to offset the negative aspects. This suggests that despite the size of the economy or its dependency on the tourism industry, the residents are content with their region and chosen lifestyle. This lack of difference might suggest that societal differences 
that exist between regions are spatial differences, which were minimised in this research by only selecting case studies from within Queensland, Australia.

Nonetheless, while the mode remained unchanged, the proportion of respondents at the mode changed with tourism having a positive relationship with the Murweh Shire and Hervey Bay's society, but a negative relationship with the Gold Coast's society. This reflects conclusions in previous studies, which suggest that as a tourism destination develops, its society is negatively impacted (Butler, 1980). These findings also support, to some extent, the argument that more rapid and intensive tourism development can result in less beneficial impacts for the community than small-scale development (Ratz, 2000); thereby providing insight into why some studies find that tourism impacts are positive, while others find that it is negative. However, there was little significant difference in the impact of tourism on the three regions societies and thus it is more likely that the spatial and cultural differences influence whether tourism has a positive or negative affect on a region's society.

Some researchers have found that during transition, a construction region may have an inherent stability and a greater capacity for dealing with shocks (Macaulay, 1994). This research found that Hervey Bay's scenarios had the greatest variability from the base case ranging by 37.9 percentage points. This was followed by the Murweh Shire (29.1 percentage points) and the Gold Coast (9.8 percentage points). Thus the construction region, with its rapid development, is more likely to have greater changes in the society as a result of a small shift in tourism compared to the inception and urban regions. This identifies an inherent instability in the region, supporting that the region is undergoing transformation and the hypothesis that, as tourism increases and impacts more heavily on a region, the residents' perceptions of the impact of tourism also increase (Diedrich \& Garcia-Buades, 2009). This finding can be more closely linked to studies that indicate that tourism development becomes less favourable beyond a certain threshold, or growth limit, where the perceived benefits no longer outweigh the negative impacts (Ap, 1992). This supports the transformation theory, which suggests that during radical change, or construction of a destination, the system is not in equilibrium (Loye \& Eisler, 1987).

The base case also revealed that tourism had the greatest positive social impact on the Murweh Shire, with $90 \%$ of the respondents falling between Strongly Agree and Agree on the 5-point social index (Figure 2). This compares to $71 \%$ and $65 \%$ of respondents that fell between Strongly Agree and Agree for Hervey Bay and the Gold Coast, respectively. 
Notably, tourism was viewed positively by the residents in all three regions, which supports a social assessment undertaken on the Gold Coast, which indicated that residents are positively disposed towards tourism and its impact on the community and considered tourism to be positively impacting on their way of life (Faulkner, 2003). Similarly, tourism has been found to have a positive impact on quality of life and that residents' prefer tourism development over the preservation of a quiet lifestyle (Zhong, Deng \& Xiang, 2007). Some research has argued that negative social impacts arise in the early stages of tourism development (Moyle et al., 2010). However, these results suggest that residents perceive the positive aspects of tourism to outweigh the negative impacts on society in the inception region. Indeed, no significant difference was found in how tourism was impacting on the three regions societies, thus the region's stage of tourism transformation may not affect its residents' view of their lifestyle and the impact of tourism.

This may be caused by the structure of the society being closely related to spatial factors, which may relate to the cultural context of the case studies. This follows Myers and Diener (1995) who suggest that a person's happiness is linked to culture and Smith (1979) who argued it is related to geography or spatial differences. The finding that residents believe the positive impacts of tourism outweigh negative impacts on their community and way of life follows the popular view within the resident perception literature (Moyle et al., 2010; Keogh, 1990). This implies that tourism planning for society requires location specific planning (Ruhanen, 2004). However, as this research found no significant differences between three regions in Queensland, specific planning may not necessarily need to be at the local level. However, this may only apply to Queensland, where the Queensland Government and Tourism Queensland play an active role in the tourism industry and its planning. Thus, the Queensland regions have a tourism system that is comparably managed, resulting in the impacts of tourism being similar on society.

\section{INSERT FIGURE 2 HERE}




\section{The relationship between the tourism industry and environment}

\section{Modelling Results}

Table 4 presents the GOLR results estimating the impact of the tourism variables [Tourism1, Tourism2, Tourism3 and Tourism4] on the environmental index [Envirlikert]. The Murweh Shire and Hervey Bay models were statistically significant, unlike the Gold Coast model, suggesting that other factors not included in the model significantly influence the Gold Coast's environment. The parallel lines assumption was imposed for Tourism1, Tourism 3 and Tourism4 in the Hervey Bay model and for all variables in the Gold Coast model. The only statistically significant variable was Tourism2 in the Hervey Bay and Gold Coast models. However, Table 4 shows that Tourism 2 for the Shire exhibited issues of multicollinearity, possibly because residents perceive that the impact of tourism on the environment may be a factor limiting the growth of tourism in the Shire, supporting Hunter (2002) who noted that there can be environmental limits to tourism growth.

\section{INSERT TABLE 4 HERE}

\section{Scenario Results}

The literature tends to observe tourism having a negative impact on the environment (Aguilo, Alegre \& Sard, 2005). While some researchers argue that the impacts have greater connotations for the later stages of development (Alexandra \& Riddington, 2007), others propose they impact on the early stages (de Lacy, Battig, Moore \& Noakes, 2002). This research found that tourism was negatively related to the Murweh Shire and Hervey Bay's environment; but positively to the Gold Coasts, despite the residents considering the urban region to have the poorest environment. This may indicate that the impact of tourism and tourism development had already occurred and growth was considered unlikely to have any further adverse impacts on an already deteriorated environment. Indeed, tourism was seen as a positive influence on the environment. An example of this on the Gold Coast is the proposed implementation of tourism on South Stradbroke after mining ceases (The Friends of Stradbroke Island Association, 2010).

However, the environmental impact of tourism at the base case was found to be positive for Hervey Bay, with $70 \%$ of respondents falling between Strongly Agree and Agree, 
compared to $29 \%$ and $2 \%$ from the Murweh Shire and Gold Coast, respectively. Owing to their tourism industries being negatively related to the environment, the growth in tourism scenario resulted in fewer respondents in the Shire (down 8\%) and Hervey Bay (down 20\%) viewing the environment positively. However, the Gold Coast's tourism industry's positive relationship with the environment saw the increase in tourism result in more respondents in the Gold Coast (up 2\%) viewing the environment positively. Notably, the growth in tourism scenario resulted in 18\% fewer respondents in the Gold Coast and 2\% fewer in Hervey Bay viewing the environment negatively, but increased the respondents who viewed the environment negatively in the Murweh Shire by 3\%. The decline in tourism resulted in $43 \%$ more respondents in the Shire and $17 \%$ more in Hervey Bay viewing the environment positively, while the Gold Coast declined 1\% (Figure 3).

The residents in an inception region have previously been found to consider tourism growth to impact negatively on the environment (Johnson, Snepenger \& Akis, 1994). Thus, a paradox is observed here, in that inception regions are more dependent on tourism as a diversification tool to stimulate growth, but tourism adversely affects these regions' environment more significantly. This supports the view that as tourism and the economy develop, there are increasingly negative environmental changes (Cater, 2004). Consequently, environmental issues are more noticeable as the development process proceeds, which is in line with the literature identifying a time lag between economic progress and its impact on society and that this lag is even more profound for the environment. The environment consequences of tourism will not be felt by present generations, but by future generations (Ogburn, 1965).

Of the three regions, the Murweh Shire's environment had the greatest variability resulting from a change in tourism, with the scenarios ranging by 57.1 percentage points around the base case. This could be associated with the Shire being less developed and the environment relatively 'untouched' in comparison with Hervey Bay and the Gold Coast, and therefore more vulnerable to significant degradation. In contrast, the Gold Coast had the least environmental variability associated with tourism, with the scenarios ranging by 34.5 percentage points from the base case.

\section{INSERT FIGURE 3 HERE}




\section{Conclusion and Future Research}

Clearly tourism can transform a region's economy, environment and society. Previously, researchers suggested an inverse relationship between tourism development and the economy, society and environment (Gunn, 1988), while others indicated that the inverse relationship is only with the society and the environment (Carter, 2004). A region's stage of transformation may determine how the region responds to tourism impacts and changes (Prideaux, 2000). Yet there is a lack of clarity surrounding how tourism impacts on the triple bottom line across the three main phases of the transformation process.

This paper further explored the impact of tourism on the triple bottom line by considering these relationships across the three main phases of the tourism transformation process using a counterfactual scenario planning strategy. It was determined that the relationships between tourism and the economy, society and environment are extremely complex, dependent on the stage of transformation and interrelated yet variable. A number of notable differences were found across the phases of tourism transformation, confirming the supposition that the phases are not homogenous.

Residents' perceptions of tourism as being important to their economy was strongly positive in the inception region, moderately negative in the construction region and strongly negative in the urban region. The strong positive relationship in the inception region could reflect that tourism is just starting to develop and the residents are anticipating the on-going agricultural decline. They recognise that tourism development can diversify and sustain the economy. The results indicate that in the urban region residents only recognised the importance of tourism when there was a lack of development or tourism was declining. However, when it is declining, the residents perceived the economic importance of tourism more acutely than the other regions, suggesting that in urban regions, residents may take the benefits of tourism activity for granted. Thus, there is a need for the industry to promote and lobby government and residents in the later stages of development, as the development focus can shift away from tourism, allowing declines to occur.

There was no significant difference between the regions' societies, or how tourism impacted on the societies, across the three main phases of the transformation process. This contrasts with previous research that found that negative social impacts often arise in the early stages of tourism development (Moyle et al., 2010), or that tourism has an inverse relationship with a region's society (Carter, 2004). Instead, this research suggests that the 
societal impact of tourism is complicated by spatial factors. However, the constructing region had the most variability in its scenarios of residents' perceptions of the societal impacts of tourism, implying that their opinions of how tourism impacts on their way of life can change more dramatically than in the other regions. For tourism management this implies that managing community perceptions of tourism development is most critical during the construction phase, and may adversely affect host-guest interactions and the composition of the society in both the construction and urbanisation phases. Moreover, while not significantly different in magnitude, tourism was found to have a positive relationship with the inception and construction region's society, but a negative relationship with the urban region's society. These differing relationships may provide insight into why some studies find that tourism impacts are positive, while others find them negative.

While the urban region had the least positive environmental rating, tourism actually had a positive relationship, albeit with low variability, with the region's environment. This suggests that tourism is not currently negatively affecting the urban region's environment, with other factors more likely to be impacting on the urban regions environment, such as other industries, a growing population or climate change. In contrast, the inception region had the most positive environmental rating, yet tourism was having the greatest negative impact on the environment in this region. The inception region's environment was also found to be more sensitive to a change in tourism than the other regions, possibly because it was less economically developed and more environmentally preserved than the other two regions. This paradox concurs with the literature that the impact of tourism on the environment should be carefully managed from the beginnings of tourism development and implies a need for long-term strategies that consider change across generations and actively involves residents in the planning process (Jamal \& Getz, 1995). It is recommended that tourism planning takes a responsible approach by being based on the goals and priorities of residents and minimising the negative environmental impacts of tourism.

In addition to the findings above, this research further contributes to the literature by employing GOLR and extending the models using a counter-factual scenario planning strategy. This is the first time that this econometrics technique has been applied in tourism research. It provides destination managers with a tool for assessing and understanding longrange tourism transformation and its impacts. Future research should expand the number and type of case studies to ensure more diverse contexts and international examples, thus testing 
and refining the theory and decision-making tools developed here. Further research could also incorporate more objective measures of the regions' structures into the models, such as economic results from CGE models, crime statistics or climate indicators. This would expand the number of variables composing the indexes and allow weaker indicators to be dropped from the indexes. With both subjective and objective measures in the indexes, the measurement system would be strengthened, providing more accurate insight into these factors and increasing the indexes' reflection of reality.

\section{Acknowledgements}

The authors would like to thank Dr. Son Nghiem for his helpful comments. 


\section{References}

Abreu, M. N. S., Siqueira, A. L., Cardoso, C. S., \& Caiaffa, W. T. (2008). Ordinal logistic regression models: application in quality of life studies. Cad Saude Publica, 24(4), $581-591$.

Aguilo, E., Alegre, J., \& Sard, M. (2005). The persistence of the sun and sand tourism model. Tourism Management, 26, 219-231.

Akama, J. S., \& Kieti, D. (2007). Tourism and Socio-economic Development in Developing Countries: A Case Study of Mombasa Resort in Kenya. Journal of Sustainable Tourism, 15(6), 735-748.

Alexandra, J., \& Riddington, C. (2007). Redreaming the rural landscape. Futures, 39(2007), 324-339.

Andereck, K. L., \& Vogt, C. A. (2000). The Relationship between Residents' Attitudes towards Tourism and Tourism Development Options. Journal of Travel Research, 39(1), 27-36.

Ap, J. (1992). Residents' perceptions on tourism impacts. Annals of Tourism Research, 19(4), 665-690.

Ap, J., \& Crompton, J. L. (1998). Developing and testing a tourism impact scale. Journal of Travel Research, 37(2), 120-130.

Asah, S. T. (2008). Empirical Social-Ecological System Analysis: From Theoretical Framework to Latent Variable Structural Equation Model. Environmental Management, 42(2008), 1077-1090.

Bender, R., \& Grouven, U. (1997). Ordinal logistic regression in medical research. Journal of the Royal College of Physicians of London, 31, 546-551.

Bramwell, B. (2003). Maltese Responses to Tourism. Annals of Tourism Research, 30, 581605.

Brant, R. (1990). Assessing proportionality in the proportional odds model for ordinal logistic regression. Biometrics, 46, 1171-1178.

Brooks, A. C. (2008). Gross National Happiness: Why Happiness Matters for America and What We Can Do to Get More of It. New York: Basic Books. 
Buhalis, D. (2000). Marketing the competitive destination of the future. Tourism Management, 21, 97-116.

Butler, R. (1980). The concept of a tourism area cycle of evolution: implications for management of resources. Canadian Geographer, 24, 5-12.

Campbell, L. M. (1999). Ecotourism in rural developing communities. Annals of Tourism Research, 26(3), 534-553.

Carmichael, B. A. (2000). A matrix model for resident attitudes and behaviours in a rapidly changing tourist area. Tourism Management, 21(6), 601-611.

Carter, R. W. (2004). Implications of sporadic tourism growth: extrapolation from the case of Boracay Island, The Philippines. Asia Pacific Journal of Tourism Research, 9(4), 383-404.

Chatterjee, S., \& Hadi, A. (2006). Regression Analysis by Example. Hoboken, New Jersey: John Wiley \& Sons.

Chen, K. C. (2004). Decision support system for tourism development: system dynamics approach. The Journal of Computer Information Systems, 45(1), 104-113.

Costanza, R., Fisher, B., Ali, S., Beer, C., Bond, L., Boumans, R., . . Snapp, R. (2008). An integrative approach to quality of life measurement, research, and policy. Surveys and Perspectives Integrating Environment and Society, 1, 11-15.

Daconto, G., \& Sherpa, L. N. (2010). Applying Scenario Planning to Park and Tourism Management in Sagarmatha National Park, Khumbu, Nepal. Mountain Research and Development, 30(2), 103-112.

de Lacy, T., Battig, M., Moore, S., \& Noakes, S. (2002). Public / Private Partnerships for Sustainable Tourism: Delivering a Sustainability Strategy for Tourism Destinations. Gold Coast: Sustainable Tourism Cooperative Research Centre.

Dickinson, J. E., \& Robbins, D. (2008). Representations of tourism transport problems in a rural destination. Tourism Management, 29, 1110-1121.

Diedrich, A., \& Garcia-Buades, E. (2009). Local perceptions of tourism as indicators of destination decline. Tourism Management, 30(2009), 512-521. 
Duffield, B. S., \& Long, J. (1981). Tourism in the highlands and islands of Scotland rewards and conflicts. Annals of Tourism Research, 8(3), 403-431.

Dwyer, L., Edwards, D., Mistilis, N., Roman, C., \& Scott, N. (2009). Destination and enterprise management for a tourism future. Tourism Management, 30(2009), 63-74.

Faulkner, B. \& C. Tideswell (1997). A framework for monitoring community impacts of tourism. Journal of Sustainable Tourism, 5(1): 3-28

Faulkner, B. (2003). Rejuvenating a maturing destination: The case of the Gold Coast. In L. Fredline, L. Jago \& C. Cooper (Eds.), Progressing Tourism Research: Bill Faulkner. Clevedon: Channel View Publications.

Fredline, L., Deery, M., \& Jago, L. (2005). Social impacts of tourism on communities. Retrieved 11 June, 2009, from www.surfcoast.vic.gov.au/Tourism/Documents/Social_Impacts_of_Tourism(05).pdf

Gladstone Regional Council. (2008). Community Values Survey. Retrieved 21 May, 2009, from http://www.gladstonerc.qld.gov.au/forms/commValue/commValue.cfm

Gonen, A. (1981). Tourism and Coastal Settlement Processes in the Mediterranean Region. Ekistics, 48(290), 378-381.

Gössling, S., \& Schumacher, K. P. (2010). Implementing carbon neutral destination policies: issues from the Seychelles. Journal of Sustainable Tourism, 18(3), 377-391.

Gunn, C. (1988). Tourism Planning (2nd ed.). New York: Taylor \& Francis.

Hall, D. R. (2004). Tourism and Transition: Governance, Transformation and Development. Wallingford: CABI.

Harrill, R. (2004). Residents' attitudes toward tourism development: a literature review with implications for tourism planning. Journal of Planning Literature, 18(251-266).

Holmes, J., Charles-Edwards, E., \& Bell, M. (2005). Population Dynamics in Rural and Remote Queensland. Brisbane: Queensland Centre for Population Research, School of Geography, Planning and Architecture, The University of Queensland.

Imai, K., Keele, L., Tingley, D., \& Yamamoto, T. (2011). Unpacking the black box of causality: Learning about causal mechanisms from experimental and observational studies. American Political Science Review, 105(4), 765-789. 
Jamal, T., \& Getz, D. (1995). Collaboration theory and community tourism planning. Annals of Tourism Research, 22(1), 186-204.

Johnson, J. D., Snepenger, D. J., \& Akis, S. (1994). Residents' perceptions of tourism development. Annals of Tourism Research, 21(3), 629-642.

Keogh, B. (1990). Public Participation in Community Tourism Planning. Annals of Tourism Research, 17(3), 449-465.

Lindeboom, M., \& van Doorslaer, E. (2004). Cut-point shift and index shift in self-reported health. Journal of Health Economics, 23(6), 1083-1099.

Long, J. S. (1997). Regression models for categorical and limited dependent variables. Thousand Oaks, CA: Sage.

Long, J. S., \& Freese, J. (2006). Regression models for categorical dependent variables using Stata (2nd ed.). College Station, Texas: Stata Press.

Loye, D., \& Eisler, R. (1987). Chaos and Transformation: Implications of non-equilibrium theory for social science and society. Behavioral Science, 32, 53-65.

Macaulay, J. F. (1994). Tourism and the Transformation of Cuba. The Cornell Hotel and Restaurant Administration Quarterly, June(1994), 16-21.

McLennan, C. (2009). The tourism transformation process: an inquiry into the three main process phases. Paper presented at the Universitas 21 International Graduate Research Conference: Sustainable Cities for the Future, Melbourne and Brisbane, Australia.

McLennan, C., Ruhanen, L., Ritchie, B., \& Pham, T. (2012). Dynamics of Destination Development: Investigating the application of Transformation Theory. Journal of Hospitality and Tourism Research, 36(2), 164-190.

Milne, S., \& Ateljevic, I. (2001). Tourism, economic development and the global-local nexus: theory embracing complexity. Tourism Geographies, 3(4), 369-393.

Moyle, B. D., Croy, W. G., \& Weiler, B. (2010). Community Perceptions of Tourism Impacts on Bruny and Magnetic Islands. Asia Pacific Journal of Tourism Research, 15(3), 353-366.

Murweh Shire Council. (2005). Corporate Plan 2007-2011. Murweh Shire.

Myers, D. G., \& Diener, E. (1995). Who is happy? Psychological Science, 6(1), 10-19. 
New Zealand's City Councils. (2008). Quality of life in New Zealand's Cities Retrieved 12th September, 2009, from http://www.bigcities.govt.nz/

Ogburn, W. F. (1965). Technology as Environment. In W. F. Ogburn (Ed.), On Cultural and Social Change: Selected Papers (pp. 78-85). Chicago: The University of Chicago Press.

Organisation for Economic Co-operation and Development. (2008). Key Environmental Indicators. Retrieved 11 June, 2009, from www.oecd.org/dataoecd/20/40/37551205.pdf

Pavlovich, K. (2003). The evolution and transformation of a tourism destination network: the Waitomo caves, New Zealand. Tourism Management, 24, 203-216.

Pham, T., Simmons, D. G., \& Spurr, R. (2010). Climate change-induced economic impacts on tourism destinations: the case of Australia. Journal of Sustainable Tourism, 18(3), 449-473.

Prideaux, B. (2000). The resort development spectrum - a new approach to modeling resort development. Tourism Management, 21(3), 225-240.

Prideaux, B., Laws, E., \& Faulkner, B. (2004). Events in Indonesia: exploring the limits to formal tourism trends forecasting methods in complex crisis situations. Tourism Management, 24(2003), 475-487.

Ratz, T. (2000). Residents' Perceptions of the Sociocultural Impacts of Tourism at Lake Balaton, Hungary. In G. Richards \& D. Hall (Eds.), Tourism and Sustainable Community Development (pp. 36-47). London: Routledge.

Ruhanen, L. (2004). Strategic planning for local tourism destinations: an analysis of tourism plans. Tourism and Hospitality: Planning and Development, 1(3), 239-253.

Russell, R., \& Faulkner, B. (2004). Entrepreneurship, Chaos and the Tourism Area Lifecycle. Annals of Tourism Research, 31(3), 556-579.

Schianetz, K., Kavanagh, L., \& Lockington, D. (2007). Concepts and Tools for Comprehensive Sustainability Assessments for Tourism Destinations: A Comparative Review. Journal of Sustainable Tourism, 15(4), 369-390.

Scott, D., \& McBoyle, G. (2001). Using a 'Tourism Climate Index' to examine the implications of climate change for tourism as a climate resource. Paper presented at 
the International Society for Biometeorology Proceedings of the First International Workshop on Climate, Tourism and Recreation. Retrieved December 30, 2009, from http://www.mif.uni-freiburg.de/isb/ws/report.htm.

Scott, N. (2003). Tourism Trends: Evolution of tourism product markets. The University of Queensland, Queensland, Australia.

Sergeyev, A., \& Moscardini, A. (2006). Governance of economic transitions: a case study of Ukraine. Kybernetes, 35(1/2), 90-107.

Sheehan, K. B. (2001). Email survey response rates: A review. Journal of Computer Mediated Communication, 2(6). Retrieved $30^{\text {th }}$ of June 2010, from http://jcmc.indiana.edu/vol6/issue2/sheehan.html

Simmons, R., Yonk, R., \& Fawson, C. (2010). Quality of Life: Building an Index: The Center for Public Lands and Rural Economics, Utah State University.

Smith, D. M. (1979). Where the grass is greener: living in an unequal world. Harmondsworth: Penguin.

Social Science Computing Cooperative. (2006). Making Predictions with Counter-Factual Data in Stata. Madison: UW Board of Regents, University of Wisconsin.

Sorenson, T., \& Epps, R. (2003). The role of tourism in the economic transformation of the Central West Queensland Economy. Australian Geographer, 34(1), 73-89.

Tarling, R. (2008). Statistical modelling for social researchers: principles and practice. London: Routledge.

The Friends of Stradbroke Island Association Inc. (2010). How can we save Straddie?: Why the current proposal is fatally flawed. Newsletter No. 58. Retrieved from http://savestraddie.com/site/wpcontent/woo_uploads/2011/01/2010.09_newsletter.pdf

Thompson, D., Muriel, P., Russell, D., Osborne, P., Bromley, A., Rowland, M., .. . Brown, C. (2002). Economic costs of the foot and mouth disease outbreak in the United Kingdom in 2001. Revue scientifique et technique (International Office of Epizootics), $21(3), 675-687$.

Tooman, L. A. (1997). Applications of the Life-Cycle Model in Tourism. Annals of Tourism Research, 24(1), 214-234. 
Turton, S., Dickson, T., Hadwen, W., Jorgensen, B., Pham, T., Simmons, D. G., Tremblay, P., \& Wilson, R. (2010). Developing an approach for tourism climate change assessment: evidence from four contrasting Australian case studies. Journal of Sustainable Tourism, 18(3), 429-447.

Williams, R. (2006). Generalized ordered logit/partial proportional-odds models for ordinal dependent variables. Stata Journal, 6, 58-82.

Yeoman, I., Lennon, J. J., Blake, A., Galt, M., Greenwood, C., \& McMahon-Beattie, U. (2007). Oil depletion: What does this mean for Scottish tourism? Tourism Management, 28, 1354-1365.

Zhong, L., Deng, J. \& Xiang, B. (2007). Tourism development and the tourism area life-cycle model: A case study of Zhangjiajie National Forest Park, China. Tourism Management, 29(5), 841-856. 
Table 1. Tourism, Economic, Social and Environmental Survey Results

\begin{tabular}{|c|c|c|c|c|c|c|c|c|}
\hline \multirow[b]{2}{*}{ Variable } & \multirow[b]{2}{*}{ Question } & \multicolumn{6}{|c|}{ Means } & \multirow[b]{2}{*}{ Sign } \\
\hline & & $\begin{array}{l}\text { Murweh } \\
\text { Shire }\end{array}$ & & $\begin{array}{c}\text { Hervey } \\
\text { Bay } \\
\text { City }\end{array}$ & & $\begin{array}{l}\text { Gold } \\
\text { Coast } \\
\text { City }\end{array}$ & & \\
\hline Tourism 1 & Tourism is an important industry for this region & 2.2 & $*$ & 1.5 & $*$ & 1.4 & $*$ & + \\
\hline Tourism 2 & There are no factors limiting tourism growth in this region & 2.9 & & 2.8 & & 3.1 & & + \\
\hline Tourism 3 & There are factors stimulating tourism growth in this region & 2.6 & & 2.2 & & 2.0 & & + \\
\hline Tourism 4 & The tourism industry in this region provides many jobs & 2.4 & $*$ & 1.9 & $*$ & 1.6 & $*$ & + \\
\hline \multicolumn{2}{|c|}{ Tourism average [tourlikert] } & 2.4 & $*$ & 1.8 & & 1.7 & & \\
\hline Economy 1 & This region has very urban facilities and activities & 3.2 & $*$ & 2.4 & $*$ & 2.1 & $*$ & + \\
\hline Economy 2 & This region's economy should not get any bigger (already big) & 4.0 & $*$ & 3.5 & & 3.4 & & + \\
\hline Economy 3 & This region's economy cannot get any bigger (already big) & 4.1 & & 3.9 & & 3.6 & & + \\
\hline Economy 4 & This region has everything I want and need & 3.2 & $*$ & 2.7 & & 2.4 & & + \\
\hline \multicolumn{2}{|c|}{ Economy average [econlikert] } & 3.9 & $*$ & 3.2 & $*$ & 2.9 & $*$ & \\
\hline Social 1 & Your personal health is generally excellent & 2.0 & & 2.5 & $*$ & 2.0 & & + \\
\hline Social 2 & This region has a close knit community & 2.3 & & 2.5 & & 2.8 & & + \\
\hline Social 3 & You are happy with your current lifestyle and do not want it to change & 2.4 & & 2.5 & & 2.3 & & + \\
\hline Social 4 & Tourism negatively impacts on your way of life (i.e. causes disruption and inconvenience) & 3.8 & & 3.7 & & 3.7 & & $-\dagger$ \\
\hline Social 5 & Tourism increases your social awareness and involvement & 2.4 & $*$ & 2.7 & & 2.8 & & + \\
\hline Social 6 & Tourism activity and visitors to this region are the cause of a higher rate of local crime & 4.2 & $*$ & 3.4 & & 3.4 & & $-\dagger$ \\
\hline Social 7 & There are not enough cultural or leisure activities in the region & 2.9 & & 2.9 & & 3.1 & & $-\dagger$ \\
\hline Social 8 & $\begin{array}{l}\text { Tourism promotes the development and better maintenance of public facilities which benefits local } \\
\text { residents }\end{array}$ & 2.3 & & 2.3 & & 2.3 & & + \\
\hline Social 9 & $\begin{array}{l}\text { Tourism helps to promote a better opinion of the region and encourages future tourism and/or } \\
\text { business investment }\end{array}$ & 2.0 & & 2.0 & & 2.0 & & + \\
\hline
\end{tabular}




\begin{tabular}{|c|c|c|c|c|c|c|c|c|}
\hline Social 10 & Because of tourism, there are more interesting things to do in the region (i.e. activities and events) & 2.5 & & 2.3 & & 2.0 & & + \\
\hline Social 11 & Because of tourism, there are better shopping, dining and/or recreational opportunities in the region & 3.1 & $*$ & 2.4 & & 2.1 & & + \\
\hline Social 12 & You are happy with the way tourism is developing in the region & 2.6 & $*$ & 2.2 & & 2.3 & & + \\
\hline Social 13 & You would like to see less tourism in the region & 4.2 & $*$ & 3.7 & & 3.8 & & $-\dagger$ \\
\hline Social 14 & Tourism is vital for the development of the region & 1.8 & & 1.7 & & 1.7 & & + \\
\hline \multicolumn{2}{|c|}{ Social average [soclikert] } & 2.1 & & 2.2 & & 2.1 & & \\
\hline Environmental 1 & Climate is an issue & 2.9 & & 2.6 & & 2.2 & & $-\dagger$ \\
\hline Environmental 2 & Ozone depletion is an issue & 3.0 & & 2.8 & & 2.4 & & $-\dagger$ \\
\hline Environmental 3 & Air Quality is an issue & 3.6 & $*$ & 3.1 & $*$ & 2.3 & $*$ & $-\dagger$ \\
\hline Environmental 4 & Waste generation and disposal is an issue & 2.7 & & 2.5 & & 1.9 & $*$ & $-\dagger$ \\
\hline Environmental 5 & Fresh water quality and availability is an issue & 3.2 & $*$ & 2.5 & $*$ & 1.9 & $*$ & $-\dagger$ \\
\hline Environmental 6 & Preservation of forest resources is an issue & 3.3 & $*$ & 2.5 & $*$ & 1.9 & $*$ & $-\dagger$ \\
\hline Environmental 7 & Preservation of marine life is an issue & 3.2 & $*$ & 1.8 & & 1.7 & & $-\dagger$ \\
\hline Environmental 8 & Energy use and availability is an issue & 2.5 & & 2.2 & & 2.0 & $*$ & $-\dagger$ \\
\hline Environmental 9 & Preservation of threatened species is an issue & 2.5 & $*$ & 1.9 & & 1.9 & & $-\dagger$ \\
\hline Environmental 10 & There are environmental strategies in place in the region & 2.5 & & 2.3 & & 2.4 & & + \\
\hline Environmental 11 & There are effective environmental strategies in place in the region & 2.9 & & 3.0 & & 2.8 & & + \\
\hline Environmental 12 & You or your employer could further contribute to maintaining and preserving the local environment & 2.4 & & 2.7 & & 2.5 & & $-\dagger$ \\
\hline Environmental 13 & $\begin{array}{l}\text { Tourism is negatively impacting on the local environment (i.e. excessive litter, damage to natural } \\
\text { areas) }\end{array}$ & 3.7 & $*$ & 3.1 & & 2.9 & & $-\dagger$ \\
\hline Environmental 14 & Tourism positively impacts on the local environment (i.e. helps to preserve/maintain local habitats) & 2.7 & & 2.7 & & 2.8 & & + \\
\hline Environmental 15 & $\begin{array}{l}\text { The number of visitors to the region is so high that they are negatively impacting on the } \\
\text { environment }\end{array}$ & 3.9 & $*$ & 3.3 & & 3.1 & & $-\dagger$ \\
\hline \multicolumn{2}{|c|}{ Environmental average [envirlikert] } & 2.8 & $*$ & 3.3 & $*$ & 3.6 & $*$ & \\
\hline \multicolumn{9}{|c|}{$\dagger$ Reverse coded for index; based on Likert scale where $1=$ "Strongly Agree" and $5=$ "Strongly Disagree" } \\
\hline
\end{tabular}


Table 2. Tourism Impact on the Economy [econlikert] Results

\begin{tabular}{|c|c|c|c|c|c|c|c|c|c|c|c|c|}
\hline \multicolumn{13}{|c|}{ Survey Generalised Ordered Logistic Regression } \\
\hline & \multicolumn{3}{|c|}{ Murweh Shire } & & \multicolumn{3}{|c|}{ Hervey Bay City } & & \multicolumn{3}{|c|}{ Gold Coast City } & \\
\hline $\begin{array}{l}\text { Independent } \\
\text { Variables }\end{array}$ & Coefficient & $\begin{array}{l}\text { Standard } \\
\text { Error }\end{array}$ & & & $\begin{array}{c}\text { Coeffici } \\
\text { ent }\end{array}$ & $\begin{array}{l}\text { Standard } \\
\text { Error }\end{array}$ & & & Coefficient & $\begin{array}{l}\text { Standard } \\
\text { Error }\end{array}$ & & \\
\hline \multicolumn{13}{|l|}{ Tourism 1} \\
\hline Strongly Agree & 18.4150 & 0.6392 & $* *$ & & -1.6834 & 0.4958 & & & 0.1892 & 0.9124 & & \\
\hline Agree & 1.5300 & 0.5950 & $* *$ & & -0.1213 & 0.3518 & & & -0.2413 & 0.3527 & & \\
\hline Neutral & 0.7410 & 0.2438 & $* *$ & & -0.3961 & 0.4011 & & & -0.4423 & 0.4731 & & \\
\hline Disagree & 0.3925 & 0.2644 & & & -1.8511 & 1.1829 & & & -20.1871 & 0.7685 & $* *$ & \\
\hline \multicolumn{13}{|l|}{ Tourism 2} \\
\hline Strongly Agree & 0.0242 & 0.2073 & & + & 0.4856 & 0.2624 & $*$ & + & 0.5299 & 0.2053 & $* *$ & + \\
\hline Agree & 0.0242 & 0.2073 & & + & 0.4856 & 0.2624 & $*$ & + & 0.5299 & 0.2053 & $* *$ & + \\
\hline Neutral & 0.0242 & 0.2073 & & + & 0.4856 & 0.2624 & $*$ & + & 0.5299 & 0.2053 & $* *$ & + \\
\hline \multirow[t]{2}{*}{ Disagree } & 0.0242 & 0.2073 & & + & 0.4856 & 0.2624 & $*$ & + & 0.5299 & 0.2053 & $* *$ & + \\
\hline & \multicolumn{2}{|c|}{$\begin{array}{l}\text { Prob }>F=0.0000 \\
\text { Obs }=98 \\
\text { Population }=3818\end{array}$} & & & \multicolumn{2}{|c|}{$\begin{array}{l}\text { Prob }>F=0.0200 \\
\text { Obs }=93 \\
\text { Population }=51802\end{array}$} & & & \multicolumn{2}{|c|}{$\begin{array}{l}\text { Prob }>F=0.0000 \\
\text { Obs }=115 \\
\text { Population }=423075\end{array}$} & & \\
\hline \multicolumn{13}{|c|}{$*$ Significant at $10 \% \quad * *$ Significant at $5 \%$} \\
\hline
\end{tabular}


Table 3. Tourism Impact on Society [soclikert] Results

\begin{tabular}{|c|c|c|c|c|c|c|c|c|c|c|}
\hline \multirow[b]{2}{*}{$\begin{array}{l}\text { Independent } \\
\text { Variables }\end{array}$} & \multicolumn{3}{|c|}{ Murweh Shire } & & \multicolumn{2}{|c|}{ Hervey Bay City } & \multicolumn{3}{|c|}{ Gold Coast City } & \\
\hline & Coefficient & $\begin{array}{l}\text { Standard } \\
\text { Error }\end{array}$ & & & Coefficient & $\begin{array}{l}\text { Standard } \\
\text { Error }\end{array}$ & Coefficient & $\begin{array}{l}\text { Standard } \\
\text { Error }\end{array}$ & & \\
\hline \multicolumn{11}{|l|}{ Tourism 1} \\
\hline Strongly Agree & 0.2386 & 0.2537 & & + & 0.7706 & 1.1534 & n.p. & n.p. & & \\
\hline Agree & 0.2386 & 0.2537 & & + & 0.5146 & 0.4840 & n.p. & n.p. & & \\
\hline Neutral & n.p. & n.p. & & & 74.6475 & 7.7949 & n.p. & n.p. & & \\
\hline \multicolumn{11}{|l|}{ Tourism 2} \\
\hline Strongly Agree & 0.8220 & 0.2586 & $* *$ & $\dagger$ & 0.4442 & 0.4863 & -0.1862 & 0.3546 & & \\
\hline Agree & 0.8220 & 0.2586 & $* *$ & + & 0.7620 & 0.3204 & -0.0875 & 0.2497 & & \\
\hline Neutral & n.p. & n.p. & & & 51.9873 & 7.8927 & 0.9154 & 0.2563 & $* *$ & \\
\hline \multicolumn{11}{|l|}{ Tourism 3} \\
\hline Strongly Agree & 1.0359 & 0.2552 & $* *$ & $\dagger$ & 3.7917 & 1.2967 & 1.8617 & 0.8311 & $* *$ & \\
\hline Agree & 1.0359 & 0.2552 & $* *$ & $\dagger$ & 0.5131 & 0.4774 & 0.3838 & 0.3374 & & \\
\hline Neutral & n.p. & n.p. & & & -29.7278 & 3.9652 & -1.1051 & 0.3791 & $* *$ & \\
\hline \multicolumn{11}{|l|}{ Tourism 4} \\
\hline Strongly Agree & 1.3778 & 0.3147 & $* *$ & + & -0.7408 & 0.9049 & 0.5924 & 0.4643 & & + \\
\hline Agree & 1.3778 & 0.3147 & $* *$ & + & 0.8165 & 0.5209 & 0.5924 & 0.4643 & & + \\
\hline \multirow[t]{2}{*}{ Neutral } & n.p. & n.p. & & & 66.8785 & 6.5199 & 0.5924 & 0.4643 & & + \\
\hline & \multicolumn{2}{|c|}{$\begin{array}{l}\text { Prob }>F=0.0000 \\
\text { Obs }=98 \\
\text { Population }=3818\end{array}$} & & & \multicolumn{2}{|c|}{$\begin{array}{l}\text { Prob }>F=0.0000 \\
\text { Obs }=93 \\
\text { Population }=51802\end{array}$} & \multicolumn{2}{|c|}{$\begin{array}{l}\text { Prob }>F=0.0000 \\
\text { Obs }=115 \\
\text { Population }=423075\end{array}$} & & \\
\hline $\begin{array}{l}* \text { Significant at } 1 \\
+ \text { Constraints for }\end{array}$ & rallel lines & $\begin{array}{l}* * \text { Sign } \\
\text { posed }\end{array}$ & ican & & Publishabl & ither for reas & ulticollinearit & or zero value & & \\
\hline
\end{tabular}


Table 4. Tourism Impact on the Environment [envirlikert] Results

\begin{tabular}{|c|c|c|c|c|c|c|c|c|c|c|}
\hline \multirow[b]{2}{*}{$\begin{array}{l}\text { Independent } \\
\text { Variables }\end{array}$} & \multicolumn{2}{|c|}{ Murweh Shire } & \multicolumn{3}{|c|}{ Hervey Bay City } & & \multicolumn{3}{|c|}{ Gold Coast City } & \\
\hline & Coefficient & $\begin{array}{l}\text { Standard } \\
\text { Error }\end{array}$ & Coefficient & $\begin{array}{l}\text { Standard } \\
\text { Error }\end{array}$ & & & Coefficient & $\begin{array}{l}\text { Standard } \\
\text { Error }\end{array}$ & & \\
\hline \multicolumn{11}{|l|}{ Tourism 1} \\
\hline Strongly Agree & -12.3039 & 3.3465 & -0.0662 & 0.6368 & & + & 0.5609 & 0.5184 & & + \\
\hline Agree & -0.5833 & 0.2810 & -0.0662 & 0.6368 & & + & 0.5609 & 0.5184 & & t \\
\hline Neutral & -0.3663 & 0.4101 & -0.0662 & 0.6368 & & + & 0.5609 & 0.5184 & & + \\
\hline \multicolumn{11}{|l|}{ Tourism 2} \\
\hline Strongly Agree & n.p. & n.p. & -0.8651 & 0.4884 & $*$ & & 0.4210 & 0.1967 & $* *$ & + \\
\hline Agree & n.p. & n.p. & -0.4698 & 0.2700 & $*$ & & 0.4210 & 0.1967 & $* *$ & t \\
\hline Neutral & n.p. & n.p. & 0.5170 & 0.2875 & $*$ & & 0.4210 & 0.1967 & $* *$ & + \\
\hline \multicolumn{11}{|l|}{ Tourism 3} \\
\hline Strongly Agree & 32.1733 & 6.5627 & 0.4501 & 0.4691 & & + & -0.2776 & 0.2770 & & + \\
\hline Agree & 0.5069 & 0.2681 & 0.4501 & 0.4691 & & + & -0.2776 & 0.2770 & & + \\
\hline Neutral & -0.0662 & 0.2697 & 0.4501 & 0.4691 & & + & -0.2776 & 0.2770 & & + \\
\hline \multicolumn{11}{|l|}{ Tourism 4} \\
\hline Strongly Agree & 74.5702 & 13.9935 & -0.1710 & 0.5245 & & + & -0.4980 & 0.4761 & & + \\
\hline Agree & -0.1225 & 0.2608 & -0.1710 & 0.5245 & & + & -0.4980 & 0.4761 & & + \\
\hline \multirow[t]{2}{*}{ Neutral } & -0.1841 & 0.3642 & -0.1710 & 0.5245 & & + & -0.4980 & 0.4761 & & + \\
\hline & \multicolumn{2}{|c|}{$\begin{array}{l}\text { Prob }>F=0.0000 \\
\text { Obs }=98 \\
\text { Population }=3818\end{array}$} & \multicolumn{2}{|c|}{$\begin{array}{l}\text { Prob }>F=0.0294 \\
\text { Obs }=93 \\
\text { Population }=51802\end{array}$} & & & \multicolumn{2}{|c|}{$\begin{array}{l}\text { Prob }>F=0.1914 \\
\text { Obs }=115 \\
\text { Population }=423075\end{array}$} & & \\
\hline \multicolumn{11}{|c|}{$*$ Significant at $10 \% \quad * *$ Significant at $5 \%$} \\
\hline
\end{tabular}



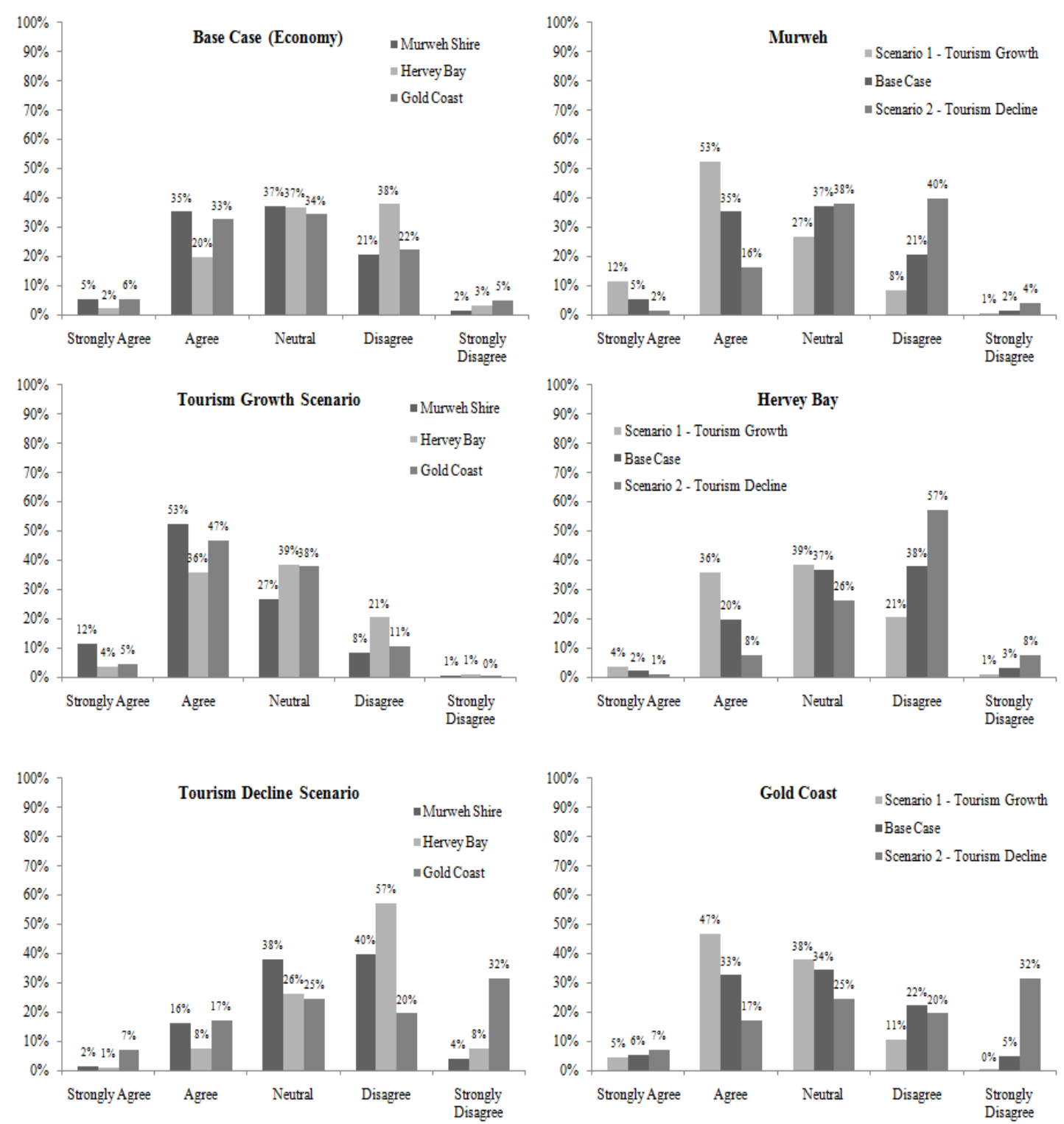

Figure 1. Charts of tourism impact on economy scenario results 

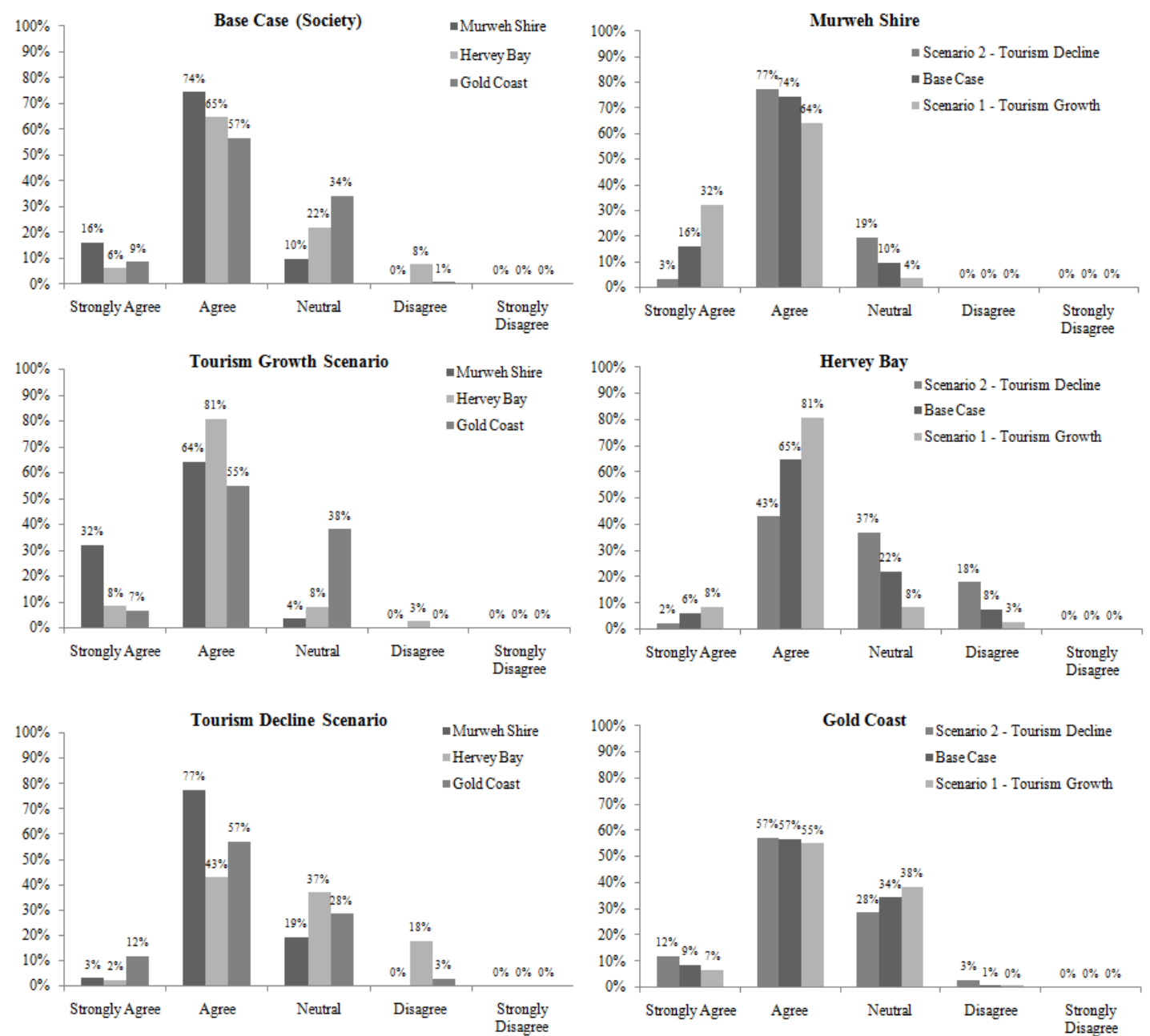

Figure 2. Charts of tourism impact on society scenario results 

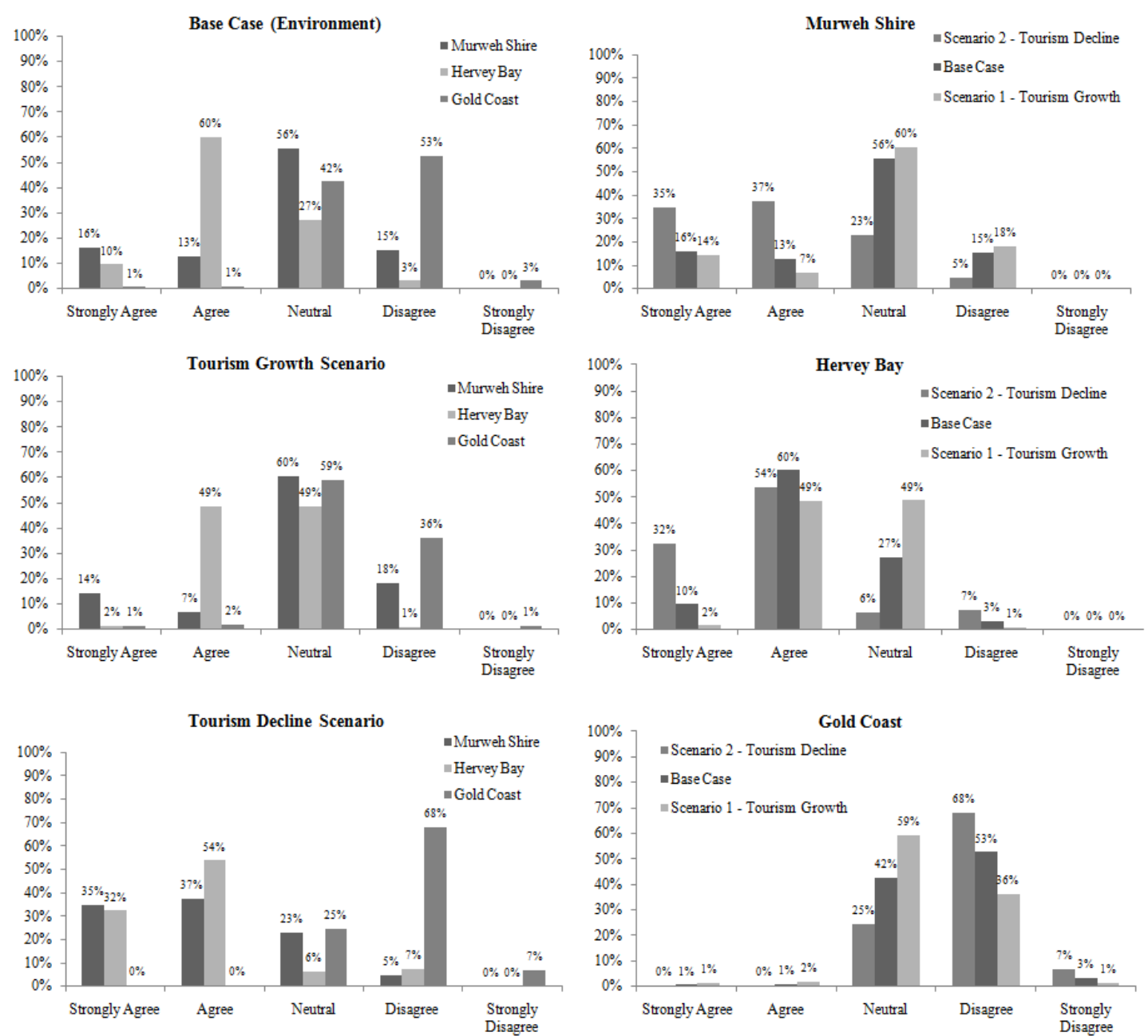

Figure 3. Charts of tourism impact on environment scenario results 